OPEN ACCESS

Edited by:

Delali A. Dovie,

University of Ghana, Ghana

Reviewed by:

Cheul Kyu Lee,

Korea Railroad Research Institute,

South Korea

Ruilin You,

China Academy of Railway Sciences,

China

*Correspondence:

Sakdirat Kaewunruen

s.kaewunruen@bham.ac.uk;

sakdirat@gmail.com

Specialty section:

This article was submitted to

Transportation and Transit Systems,

a section of the journal

Frontiers in Built Environment

Received: 31 July 2020

Accepted: 15 October 2020

Published: 16 November 2020

Citation:

Liu R, Li D and Kaewunruen S (2020) Role of Railway Transportation

in the Spread of the Coronavirus:

Evidence From Wuhan-Beijing

Railway Corridor.

Front. Built Environ. 6:590146.

doi: 10.3389/fbuil.2020.590146

\section{Role of Railway Transportation in the Spread of the Coronavirus: Evidence From Wuhan-Beijing Railway Corridor}

\author{
Rucheng Liu, Dan Li and Sakdirat Kaewunruen* \\ School of Engineering, University of Birmingham, Birmingham, United Kingdom
}

The last few months have marked a notable surge in COVID-19. The disease has infected 10 million people around the world and has gained attention in the field of research. Allegedly originating in China, the virus has spread to nearly every country. The current study aims to analyze the potential spread of the coronavirus through rail transport by considering the case of the Wuhan-Beijing railway corridor in China. It has been found that approximately 43,000 people travel daily through this railway line, which indicates a high chance for this railway line to spread the virus. This study adopts a quantitative methodology to analyze the spread of the disease due to a large number of people traveling on the Wuhan-Beijing railway line. The findings of this study establish that the railway line leaving Wuhan carries approximately 43,000 people daily. The more people travel, the higher the chances are for the spread of the disease through this railway line. In line with that, the study has also analyzed the effectiveness of control measures such as lockdown, the use of masks, sanitization, and social distancing for railway authorities as well as passengers. This study concludes by proposing new practical recommendations for further controlling the spread of the disease in Wuhan.

Keywords: COVID-19, COVID, coronavirus, railway, transportation, corridor

\section{INTRODUCTION}

Over the past few months, the world has experienced a massive outbreak of a novel coronavirus (COVID-19), which is believed to have originated in Wuhan, China. The exact source of the virus is, however, still unclear but health officials have identified that the virus immediately spreads from person to person when an infected person coughs or sneezes close to another person. Since December 2019, the virus has caused nearly 3,300 deaths in China (Jung et al., 2020). Outside China, the virus has spread to approximately 200 countries around the world and studies like (Lu et al., 2013) and (Yang et al., 2020) report that the outbreak has now been designated a global pandemic, which is justified by its spread around the world. The pandemic has resulted in many countries imposing strict lockdowns. The governments of all countries have been taking serious steps to minimize the spread of the disease. Hence, it can be stated that researchers and healthcare authorities are working hard to not only identify the causes of the virus but its cure too. 
It has been reported that the spread of the virus has been most severe in China. The BBC has reported that the coronavirus is still spreading throughout the country. Researchers and specialists have spent a great amount of time trying to identify the causes of the disease in China, but this is still not clearly known. Although a careful assessment of the disease has resulted in recognizing the methods responsible for the spread of the disease. For instance, researchers (Cascella et al., 2020) revealed that the disease spreads by a lack of distance between people. Similarly, another study analyzed (Peeri et al., 2020) how the virus transfers by physical contact between people, such as through handshakes and hugs. The findings of a study by Ayittey et al. (2020) identified the objects through which coronavirus is likely to spread, such as handrails, telephones, and door handles. The Guardian also supports this finding by stating that banknotes, door handles, and handrails are the most significant objects that transmit the disease from one person to another. This implies that places which are densely packed have the highest probability of contributing to the spread of the coronavirus. Among other places, railway stations have been ignored in the literature, which is why this study assesses the spread of the coronavirus through rail transport by considering the example of the Wuhan-Beijing railway line.

\section{Background}

With its massive outbreak, the disease has gained attention in the field of research too. Various researchers like (Balkhair et al., 2017), (Anthony et al., 2017), and (Wang et al., 2020) have dedicated studies to analyze the causes, impacts, and control measures of the coronavirus. Moreover, scholars are also attempting to carefully gauge the spread patterns of the disease so that they can be controlled. But the existing research fails to acknowledge the spread of the disease through railway transport in China. The last decade has marked a massive growth in rail transport in the country with about 3.4 billion people traveling by train in 2018. It is, therefore, essential to identify the transmission of the disease through this form of transport. This study seeks to investigate how increasing movement of people through the railway in China plays a significant role in the spread of the coronavirus. About 440 million people traveled using Wuhan's railway line for China's New Year festivities, the spread of the disease was evident (Wong, 2019). Therefore, the focus of this study has been narrowed down to evaluate the spread of the coronavirus through the WuhanBeijing railway line.

\section{Research Questions}

The findings of this study will address the following research questions:

- How does high dependence on rail transport spread the coronavirus in different cities of China?

- What is the effectiveness of the current practices and control measures for the spread of the coronavirus?

- What are the strategies to control the spread of the coronavirus through rail transport in Wuhan and Beijing?

\section{PREVIOUS STUDIES}

Since this topic is gaining increasing attention in the research frontier, it is essential to review what has already been reported so far. Thus, this section reviews previous studies on the topic.

\section{Spread Patterns of the Coronavirus in China}

Studies recognize the first known case of the coronavirus to be on December 1, 2019, in Wuhan, Hubei, after which the cases continued to increase (Zhao et al., 2020b). Ever since, the virus has spread not only through the province but throughout the whole of China too. In view of the initial spread of the disease in Wuhan, the focus of this research is also Wuhan. China is identified as the most populous country in the world. Wang reports that the country had a population of approximately 1.39 billion in 2018 with an area of 8,494 $\mathrm{km}^{2}$, as shown in Figure 1 (Wang, 2019). Wuhan, with a population of 11 million people is the seventh most populated city in China. As Figure 1 shows, Wuhan is located in the middle of China, has a convenient transport system, and so it is possible to assume that the virus can be spread to all of China from Wuhan as the center of the breakout, as shown in Figure 2.

Relating that with the coronavirus, it can be seen that a massive number of people are likely to be infected in the country. This also indicates the uncontrolled spread of the disease in China, compared to other countries (see Figure 3). The figure also shows the pattern of the disease across January, March, and May. Figure 2 highlights the massive number of coronavirus cases to be identified in Wuhan (as shown by number and dots). The total number of cases confirmed by the Chinese authorities jumped to 4,515 on January 27 , which shows an immense increase from 1,680 cases from the previous day (BBC China, 2020). This uncontrolled outbreak forced the government and health authorities in China to take multiple steps to control the disease, such as lockdowns, the ban on movement of people and transport, and a strict prohibition on public gatherings. Due to these drastic measures, the spread of the virus was controlled in the country, ultimately resulting in no new reported cases in the middle of March. Bloomberg News reports that with the passage of time, the country witnessed a gradual decrease in the number of cases identified and an increase in the number of recovering people (Bloomberg News, 2020).

\section{Rail Transport and the Spread of the Coronavirus}

With an emerging volume of research being dedicated to the spread of the coronavirus, researchers are attempting to identify the causes of the disease too. In this regard, researchers and officials have discussed the various objects which can contribute to the spread of the disease, such as those stated before. Objects used by multiple people, for instance, coffee machines in an office, ATM machines, and bathroom surfaces, contribute to the spread of the disease. Given the current situation, governments and authorities have put a strict ban on transport mechanisms (Ranasinghe et al., 2020). This situation can be justified by the 


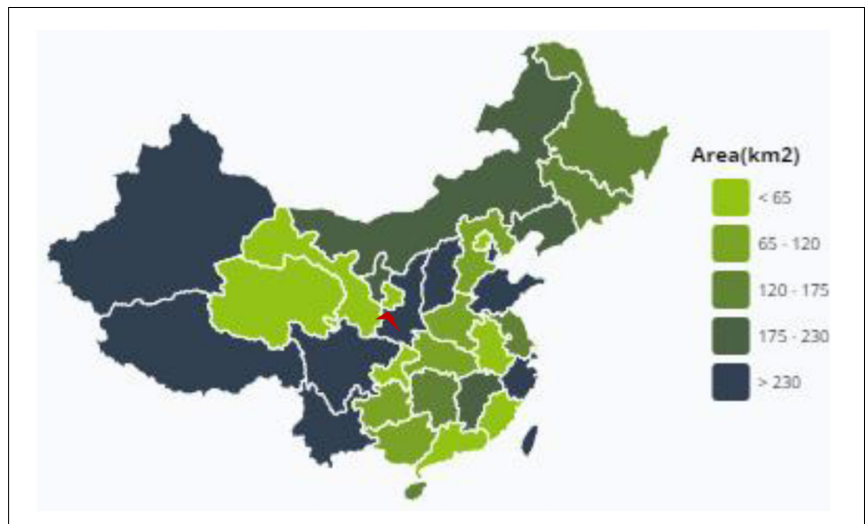

FIGURE 1 | China map (highlighted area showing Wuhan).

fact that transport vehicles, specifically trains and buses, spread the disease to a large extent. Otter et al. (2016) explains this fact by showing that, among other materials, plastic, and steel contribute significantly to the spread of the disease. The New England Journal of Medicine reported that the coronavirus can survive on materials like plastic and steel for as long as $72 \mathrm{~h}$, cardboard for approximately $24 \mathrm{~h}$, and copper for an estimated $4 \mathrm{~h}$ (Pasley, 2020). This does not imply that these objects spread the virus; instead, that interaction with these objects and then touching the face does.

By relating these findings back to the transport mechanism, it can be stated that the infrastructure of transportation relies heavily on these materials. When people use transport services, such as the railway, they are highly likely to be contaminated with the virus. This can be explained by the increasing use of handrails and ticket machines, which is why authorities disinfect them from occasionally. Shen et al. (2016) reports that rail transport are a highly popular mode of transport, with a high density of people. Since the virus spreads by the close proximity of people, the chances for the disease to rise are evident through rail transport (Shen et al., 2016). Goscé and Johansson (2018) add to these findings and state that people traveling through underground railways are prone to influenza-like diseases, which can later lead to the coronavirus. Some underground railway lines are densely packed with people, which also indicates the rise of the virus due to the lack of distance between people. Apart from people at railway stations, people living in nearby areas are also prone to the virus because of its contagious nature. This also justifies the strict lockdowns and bans on rail transport by governments in different countries. The research in this dimension concerning the spread of the virus is rare, which justifies the focus of the current study.

Given the significance of rail transport, the literature needs to pay attention to the spread of the coronavirus through transport. For instance, Wong (2019) reported on the increasing dependence of people on rail transport in China. Other studies like (Ranasinghe et al., 2020) add to these findings and state that people in China find it feasible to travel within cities through high-speed rail networks. The significance of the railway network in Wuhan is specifically emphasized because it is the hub of transportation in Hubei province. While researchers highlight the significance of rail transport and dependence on it, they are yet to investigate the spread of coronavirus due to this dependence. This research seeks to fill this gap in light of the existing literature. This study will be helpful for policymakers and the management authorities of Wuhan railway stations since it will highlight how the spread of the disease can be controlled.

\section{Confirmed Cases in China - more than 4,500}

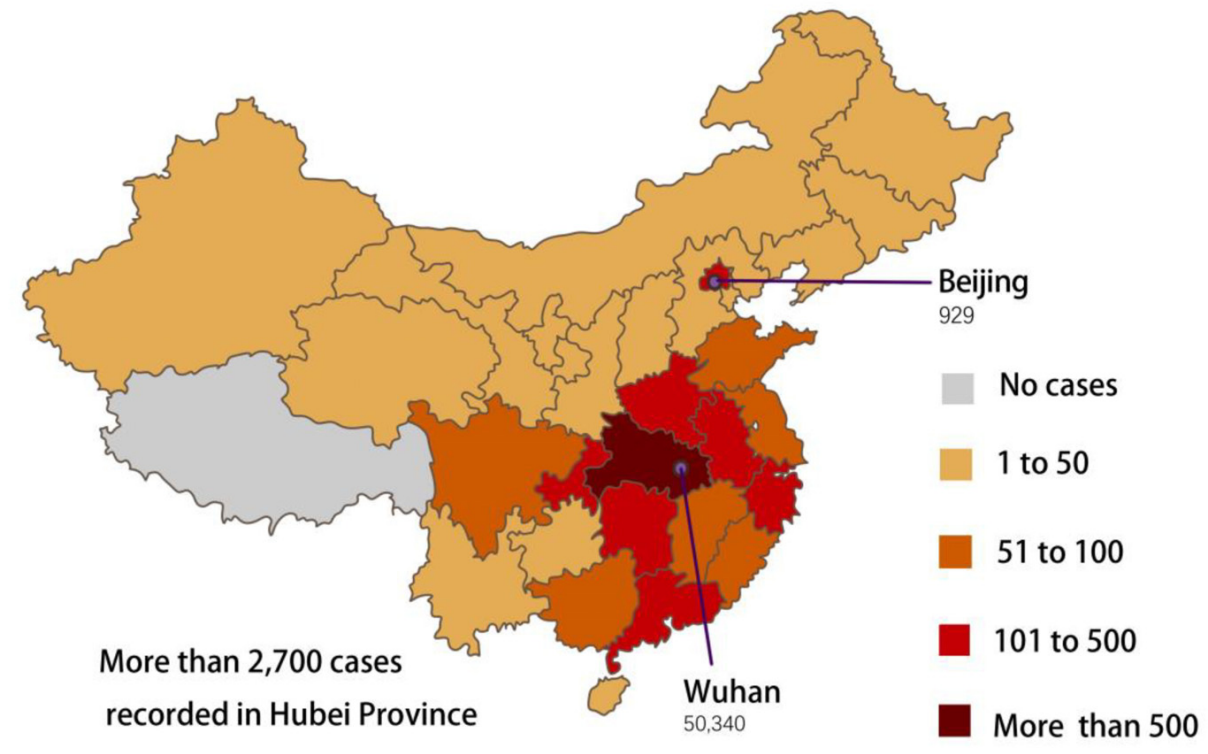

FIGURE 2 | Map showing the spread of the coronavirus in China. 


\section{Number of coronavirus cases by country (Jan, Mar, May)}

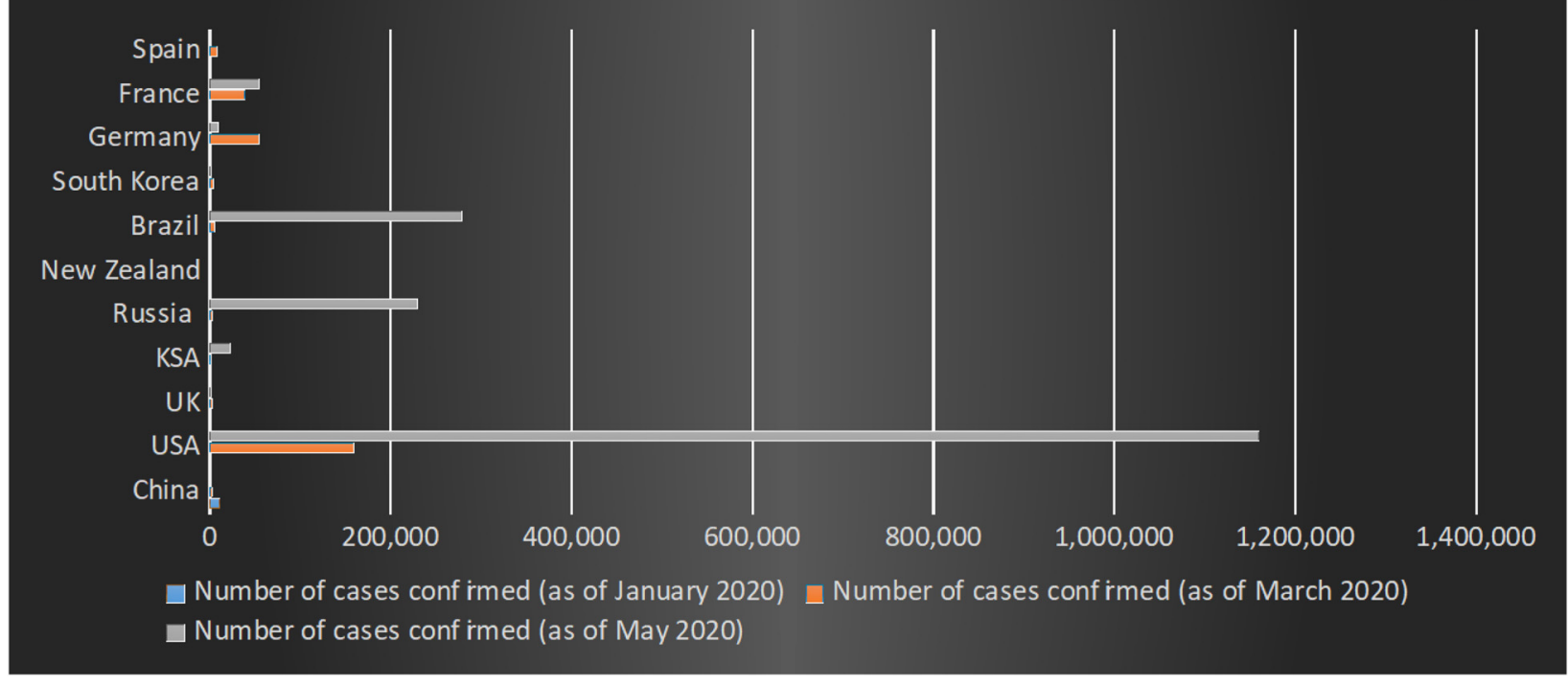

FIGURE 3 | Situation of the spread of the coronavirus in China (Self-drawn).

\section{METHODOLOGY}

Designing an effective methodology is of core significance to generate high-quality research results. Thus, this section highlights the methodological foundations of the current study.

\section{Research Method}

The current research uses quantitative methods which are assumed to generate credible and objective findings. As the question at hand is of core importance, it is essential for the researcher to generate undistorted and authentic findings. A qualitative research method was not used to gauge the spread of the coronavirus through the railway because this method takes time and is likely to be misinterpreted by the researcher (Tracy, 2019). Thus, a quantitative method was used to gauge the number of people traveling along the Wuhan-Beijing railway line and the consequent spread of the disease. In line with the chosen method, this research makes use of positivist philosophy. Through this philosophy, this research generates credible and reliable results about the spread of the coronavirus through rail transport in China. Although interpretivism can also be used for this research, positivism was chosen, to save time for the research. Positivist philosophy is also preferred because it keeps the researcher detached from the findings of this study. Care has been taken in order to make the findings regarding the spread of the coronavirus through railway stations meaningful and objective.

This methodology makes use of a deductive approach. The choice of approach can primarily be justified by the fact that a large volume of data already exist on this topic, which can be analyzed to gauge the spread of the coronavirus in China. The inductive approach would have been preferred if the research lacked any theories or testable hypotheses regarding the spread of the coronavirus in China, as also analyzed by Liu (2016). In view of the problem at hand, the appropriateness of the deductive approach is justified because only through this approach is the researcher able to empirically identify whether the coronavirus spreads through rail transport and to what extent.

\section{Sampling}

Multiple sampling techniques can be used to draw a representative sample for study. The current study relies on a random sampling technique. This technique made it easier for the researcher to select the sample respondents as per his ease. The sample respondents include railway station officials at Wuhan, who are aware of the Wuhan-Beijing railway route as well as the number of people traveling through it. Through a random sampling technique, the researcher selected a sample of 50 respondents from the administrative body of Wuhan railway station. The use of a sample of this size is justified by Heydari and Mountrakis (2018).

\section{Data Collection Strategy and Method}

The current study relies on primary data through survey questionnaires, which railway station officials in Wuhan completed. Since there is little to no evidence about the spread of the coronavirus, specifically through rail transport, collecting primary data is essential and justified. Different strategies are used for the collection of fresh data, out of which surveys have been used in this study. In accordance with the quantitative approach and positivist philosophy, the research relies on quantitative surveys (Bramley et al., 2018). A five-point Likert scale questionnaire was designed to collect data from railway officials at Wuhan railway station. Since the scope of this research is limited to the Wuhan-Beijing railway line only, questions will 
relate to the number of people traveling by rail from Wuhan to Beijing before the spread of the coronavirus, the number of cases reported as a result of that travel, and areas where the disease has spread as a result. The use of quantitative surveys is justified for this research since this strategy has allowed the researcher to gain a considerable amount of data in a comparatively short time (Clifton and Carrasco, 2018). This would not have been possible using other research strategies, like interviews and observations. The data collected has then been analyzed using descriptive analysis techniques, so as to provide a summary of the key findings regarding the spread of the coronavirus through railways in China.

\section{Ethical Considerations}

When collecting the data, the researcher has been cautious about sustaining the ethical standards for conducting research. In this regard, the researcher has taken care not to use any forceful techniques to collect data. Moreover, all the respondents were given the right to withdraw from the study at any point. As per the recommendation of Tourangeau (2018), the researcher has taken special care to maintain the confidentiality and anonymity of the respondents. Besides this, care has been taken to avoid the misuse of data collected. The studies used for the literature review have been cited appropriately. In this way, the ethical standards required for this research have been assured.

\section{RESULTS AND DISCUSSION}

The data collected through primary means has been analyzed using descriptive analysis. This section is dedicated to illustrating and discussing the key findings from the primary data. In order to extract useful meanings from the findings, the discussion is built by relating the findings of primary data with those from the existing body of knowledge.

\section{Results From Primary Data \\ Age and Experience of Respondents}

This section examines the age and experience of respondents to analyze the characteristics of the sample. The demographic analysis of a sample is useful to ensure that a suitable and respectable sample has been selected. Figures 4A,B highlight that all of the respondents are 30 years or older and have a working experience of more than 3 years. Paradis et al. (2016) highlights that experienced respondents are likely to give better responses, especially about a global issue like the coronavirus, hence the selection of these respondents is evidence of the validity of the responses.

\section{Effectiveness of Control Measures}

In view of the massive spread of the disease in China, authorities at the government and private level are taking effective measures to control its spread. It has been found that the coronavirus started in December 2019 in Wuhan and spread rapidly in the city (Ayittey et al., 2020). With a population of approximately 11.08 million people, Wuhan is one of the most populous cities in China. In addition this, the city is also a key transportation hub in
China. This implies that due to the massive number of residents, along with the movement of people from nearby cities, the chances of the spread of the disease are automatically amplified. Given these facts, authorities and the management of Wuhan railway station have taken multiple steps to control the spread of the disease. For example, the authorities complied with the regulations regarding lockdown and banned rail transportation to and from Wuhan (BBC China, 2020). As soon as the epidemic spread, the Wuhan government banned all modes of transportation to and from the city, including the railway, ferries, subways, city buses, and long-distance shuttle buses. After lifting the lockdown, the railway authorities imposed several restrictions to ensure that the disease remained controlled in the city. These restrictions included wearing masks, using sanitizers frequently, and maintaining social distance. The BBC reported that even after lifting the lockdown, only those with health clearance certificates were allowed to use the train service. According to the primary data collected here, it can be stated that a notable number of respondents agree with the fact that these practices are effective in controlling the spread of the disease (see Figure 5A). However, some of the respondents disagreed with the economic burden that lockdown created on the railway transport sector. With a massive number of people depending on the Wuhan railway network, the economic hit on this sector was notable. For instance, the lockdown resulted in an abrupt drop in the profits to Wuhan railway station. Studies refer to the loss of jobs in China as a result of the coronavirus and that implication is evident in Wuhan too. By combining these findings, it can be stated that although the measures taken by the railway authorities are deemed as impractical by some people, they are effective in the long run until the city is declared completely free from the virus.

Similarly, the primary data collected for this study has gauged the effectiveness of these control measures for the customers. As evident in Figure 5B, the majority of respondents agree with the fact that control measures like lockdown, the use of masks, sanitization, and social distancing are effective for the safety of passengers in this pandemic. The resistance of people to these control measures can be justified by the fact that lockdown has hindered a number of life events and day-to-day activities and people are forced to stay in their homes. However, the majority of the respondents agree that these control measures are effective in controlling the massive spread of the disease. People in Wuhan have been psychologically disturbed by the pandemic, which is why they are willing to comply with the regulations imposed by the government and railway authorities. It is only due to this compliance that the number of coronavirus cases in Wuhan has reduced significantly in the past few days. News reports show that in July, only four new cases were diagnosed, which were all imported from other countries. Hence, it can be deduced that control measures have been effective in controlling the spread of the disease in China.

Figures 6A,B show the amount of acknowledgment of the coronavirus by the people in Wuhan and the reduced passenger flow to and from the city. With reference to Figure 6A, it can be stated that almost all the respondents acknowledge the rapid spread of the coronavirus. As stated earlier, people in 


\section{A AGE OF RESPONDENTS}

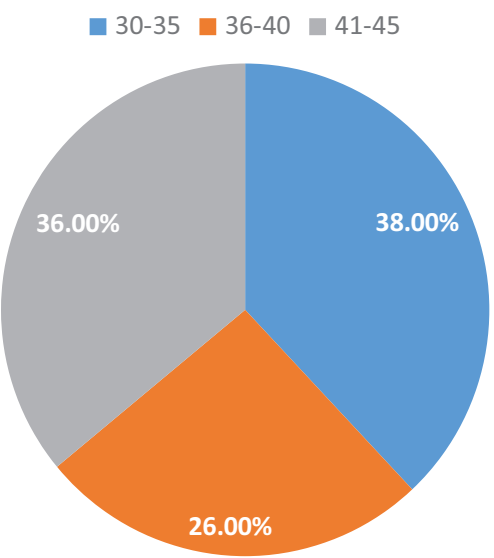

\section{B EXPERIENCE OF RESPONDENTS}
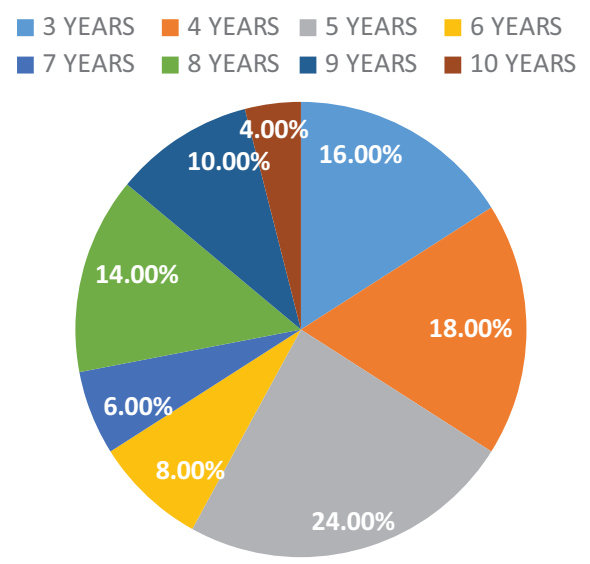

FIGURE 4 | Analysis of respondents in terms of age/experience.
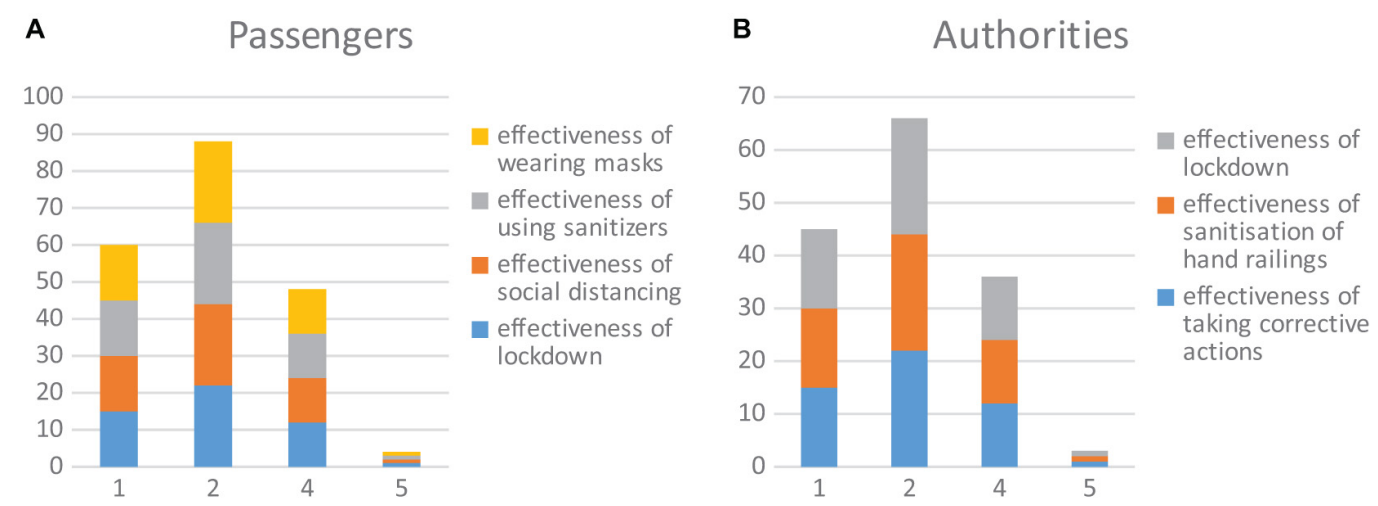

FIGURE $\mathbf{5}$ | Effectiveness of control measures taken by passengers (A) and authorities (B) of the Wuhan-Beijing railway line.
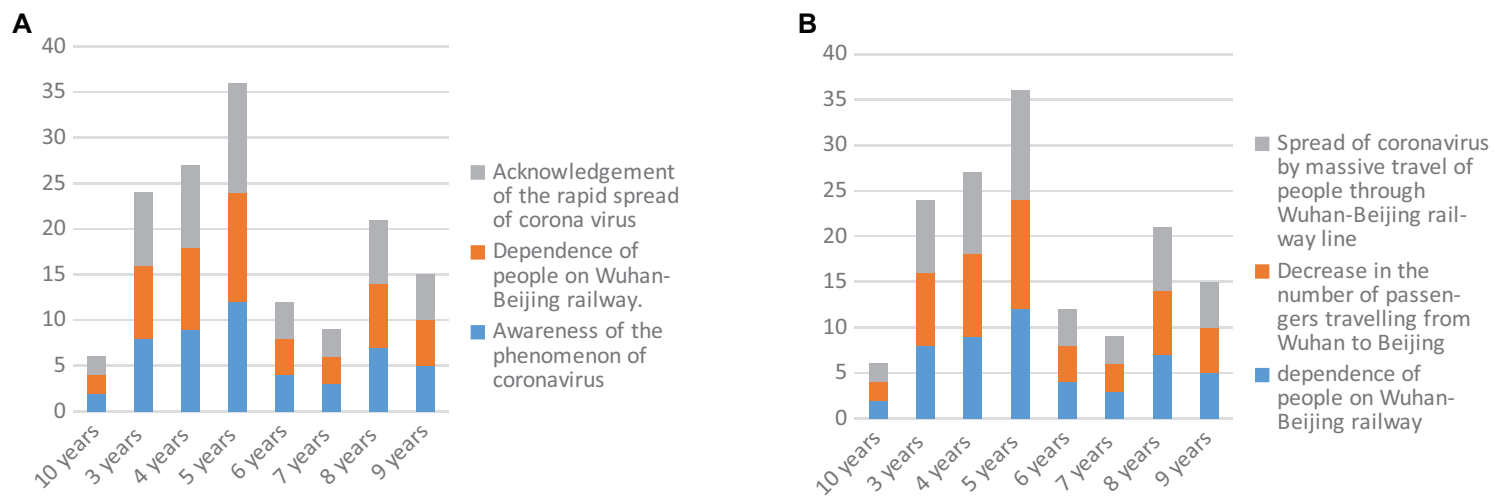

FIGURE 6 | (A) Acknowledgment of the respondents and (B) passenger flow on the Wuhan-Beijing railway line.

Wuhan significantly depend on rail transport, which is why railway transport heavily contributes to the spread of the disease. Given the increasing number of cases and consequent deaths, the flow of railway passengers has been reduced to a notable degree (see Figure 6B). The lockdown and control measures imposed by the railway authorities have been effective. Further, people in Wuhan also realize the negative connotations of the disease and thus comply with the ban on transport. It is due to 
this acknowledgment that the number of coronavirus cases and deaths in Wuhan has gradually decreased.

\section{Discussion}

The findings, in relation to the existing literature, show that the Wuhan-Beijing railway line starts from Wuhan and passes through Beijing, Guangzhou, Shenzhen, and Hong Kong (Hu et al., 2017). Apart from that, respondents reveal that approximately 43,000 passengers normally travel through this railway line every day. This is found to be in accordance with the findings of Li and Sheng (2016), who also state that this railway line is the busiest in China. By relating the findings from primary and secondary sources, it can be established that the massive number of people traveling daily through the busiest railway line in China may become carriers of the disease in all the connecting cities. The Wuhan-Beijing railway line passes through four cities. The intermixing of people across these cities suggests a rapid transmission of this disease, which is why the cases continued to increase from December 2019 to February 2020 (Figure 1). Thus, it can be stated that railways play a considerable role in the rapid transmission of the disease.

Before the government of China and the railway authority of Wuhan imposed restrictions on travel, the number of cases continued to rise. Extant studies report that Wuhan is known for the high number of passengers entering and leaving the city. It is due to this that the government of Hubei imposed a lockdown in Wuhan on January 23 2020, thereby prevent air and rail transport until further notice (Mizumoto et al., 2020). Findings from the primary data can be related to the fact that the transmission of the disease could be accredited to an increased flow of people from Wuhan to Beijing. The findings regarding the effectiveness of lockdown for railway officials and passengers can also be explained by this discussion. When the lockdown was imposed and travel from Wuhan to Beijing was banned, there was a gradual drop in the number of cases reported in China. It can be deduced that after the imposition of the strict lockdown, China experienced a break from the massive spread of the coronavirus. By combining all these findings, it can be deduced that rail transport in China has been a notable contributor to the farreaching spread of the coronavirus. Looking at the case of the Wuhan-Beijing railway line, it can unarguably be established that the immense flow of people from Wuhan to Beijing and other connecting cities along this railway line created a surge in the number of cases reported.

In view of this discussion, the effectiveness of the control measures taken by government officials for the general public can also be established. Primary data reports that although a large number of people find practices such as lockdown, wearing masks, sanitizing hands, and social distancing effective, some still disagree with this set of restrictions, holding that finding a cure is key to battling this pandemic. What needs to be understood here is the idea that practices like social distancing and quarantine are effective in controlling the massive transmission of the disease (Katz et al., 2019). The government of China and the railway authorities of Wuhan have restricted rail travel so that the spread of the coronavirus can be controlled and the wellbeing of the general public is consequently guaranteed. Given the current situation wherein the cases of the coronavirus have reduced in China, the government of China lifted the lockdown in Wuhan and other cities. Figure 2 highlights the cases of the coronavirus in different cities in China. By comparing this map with the one shown in Figure 3, it can be seen that the cases of the coronavirus in May considerably reduced.

However, the impact of this epidemic is long-lasting. In accordance with the findings of Ma et al. (2020), it can be deduced that Wuhan is no longer a transportation hub since the global epidemic has left an enduring wave of fear and social isolation among people. This indicates a need for several policy measures that the government of Wuhan should consider so as to restore the city to its previous state. Given this fact, the government of China, and especially Wuhan, should execute awareness programs for citizens. In these programs, health experts should guide the people recovering from the virus regarding their mental and psychological stability. Health experts should emphasize the positive elements of the pandemic so that anxiety, depression, and other mental health issues are reduced. In addition, the government should also devise policies to restore the economy of China (Jiao et al., 2017; Chang et al., 2020; Lai et al., 2020; Nature, 2020; Zhao et al., 2020a). In this regard, the government should specifically promote online businesses in the country. The reason behind this is the fact that people are extremely scared to go out for professional or leisure purposes, even since the epidemic has diminished (VOA News, 2020). In order to satisfy the shopping needs of the citizens, the government of China should stimulate businesses to transfer their setups to digital settings. This will create a win-win situation, wherein businesses will be able to overcome the loss they have been bearing and consumers will be able to obtain the products and services they need online.

\section{Distance and the Spread of the Coronavirus}

One of the most important aspects to note in this topic is the spread of coronavirus due to distance. It has been seen that it is due to rail transport that a considerable number of COVID cases emerged in Wuhan. But the existing research fails to acknowledge the role of distance in the spread of coronavirus disease in China. VOA News (2020) reports that the districts that are closer to the Wuhan railway station have more coronavirus cases than the ones that are farther from it (see Figure 1). By analyzing the matter in deeper detail, it can be stated that since railway stations, especially the one in Wuhan, are massively crowded, travelers are more likely to be infected by the virus. When they travel from the railway station into the city, they can transmit the virus to people who are in close vicinity to the railway station.

Findings from the primary data shown in Tables 1-3 reveal that the spread of coronavirus can be greatly accredited to people traveling from Wuhan to other cities. By relating the findings with the existing studies, it can be evaluated that a massive movement of people from and to Wuhan and its outskirts resulted in a notable spread of the disease. Xinhua news (Xinhua, 2020) reports a prominent number of cases in the Wuchang, Jianghan, and Qiaokou districts, which are in close proximity to Wuhan railway station. This is owing to the fact that the railway line passing through Wuhan ends at Zhangzhou, which is $980 \mathrm{~km}$ from Wuhan. Studies report that approximately 43,000 
TABLE 1 | Summary of data collection procedure (Self-drawn).

\begin{tabular}{ll}
\hline Data collection & Details \\
\hline Data & $\begin{array}{l}\text { Collection through questionnaires from railway station } \\
\text { officials in Wuhan }\end{array}$ \\
Procedure & $\begin{array}{l}\text { Administering the questionnaires through email to } \\
\text { managers }\end{array}$ \\
Data use & $\begin{array}{l}\text { Descriptive data analysis through frequency tables } \\
\text { Lata alignment with } \\
\text { research questions }\end{array}$ \\
\hline
\end{tabular}

TABLE 2 | Views of the respondents regarding the spread of the disease.

\begin{tabular}{lccc}
\hline Experience & $\begin{array}{c}\text { Awareness of } \\
\text { the } \\
\text { phenomenon of } \\
\text { the coronavirus }\end{array}$ & $\begin{array}{c}\text { Dependence of } \\
\text { people on the } \\
\text { Wuhan-Beijing } \\
\text { railway. }\end{array}$ & $\begin{array}{c}\text { Acknowledgments } \\
\text { of the rapid } \\
\text { spread of the } \\
\text { coronavirus }\end{array}$ \\
\hline 10 years & 2 & 2 & 2 \\
3 years & 8 & 8 & 8 \\
4 years & 9 & 9 & 9 \\
5 years & 12 & 12 & 12 \\
6 years & 4 & 4 & 4 \\
7 years & 3 & 3 & 3 \\
8 years & 7 & 7 & 5 \\
9 years & 5 & 5 & 50 \\
Grand total & 50 & 50 & 7 \\
\hline
\end{tabular}

TABLE 3 | Passenger flow on the Wuhan-Beijing railway line and the spread of the coronavirus.

\begin{tabular}{lccc}
\hline Experience & $\begin{array}{c}\text { Dependence of } \\
\text { people on the } \\
\text { Wuhan-Beijing } \\
\text { railway }\end{array}$ & $\begin{array}{c}\text { Decrease in the } \\
\text { number of } \\
\text { passengers } \\
\text { traveling from } \\
\text { Wuhan to Beijing }\end{array}$ & $\begin{array}{c}\text { Spread of the } \\
\text { coronavirus by massive } \\
\text { travel of people on the } \\
\text { Wuhan-Beijing } \\
\text { railway line }\end{array}$ \\
\hline 10 years & 2 & 2 & 2 \\
3 years & 8 & 8 & 8 \\
4 years & 9 & 9 & 9 \\
5 years & 12 & 12 & 12 \\
6 years & 4 & 4 & 4 \\
7 years & 3 & 3 & 3 \\
8 years & 7 & 7 & 5 \\
9 years & 5 & 5 & 50 \\
Grand total & 50 & 50 & 7 \\
\hline
\end{tabular}

passengers travel daily through the railway lines in Wuhan. Every train that departs from Wuhan station passes through its nearby districts, particularly Wuchang, Jianghan, and Qiaokou. It has been observed that travelers reaching Wuhan railway station take taxis to travel to their desired locations. When these taxis pass through nearby districts, chances for the spread of the disease automatically increase. This implies that the spread of the coronavirus is also dependent upon the distance between cities (see Figure 7). By relating the discussion with the research questions, it can be deduced that railway traffic, passing through different locations near Wuhan, plays a significant role in the spread of the coronavirus.
According to Shen et al. (2020), the virus spreads through sneezing, coughing, nasal discharge, and the touch of an infected person. This implies that when a large number of infected people pass through the nearby districts of Wuhan railway station, such as Wuchang, Jianghan, and Qiaokou, they are likely to infect the people in those districts. The spread of the disease in the three stated districts is quite high because people flow into Wuhan to pass through these districts. Even if incoming people do not stay in these areas, the fact that these three districts are very close to Wuhan justifies that these districts reflect a more critical spread pattern of the coronavirus than districts that are farther from Wuhan.

Apart from that, the distance of different cities from Wuhan also plays a role in spreading the disease to multiple locations. This can be demonstrated by using the examples of two cities that are located alongside the Wuhan-Beijing railway line: Xinyang and Anyang. It can be observed that the situation of the coronavirus in Xinyang is worse than that in Anyang. The cases reported in Xinyang are almost equal to those reported in the Wuhan province, which is even more populated than Xinyang. This massive spread in Xinyang can be accredited to the closer proximity of Xinyang to Wuhan. Singhal (2020) shows that the virus spreads through the close proximity of people. When a massive number of people gather in Wuhan, there are increased chances of them infecting people living in the nearby district of Xinyang. This discussion further affirms that the coronavirus is likely to spread over the short distance between cities and districts. Further, the spread of disease due to the short distance can also be explained by the rapid movement of people in Xinyang to Wuhan. The distance between the two cities is a mere $216 \mathrm{~km}$ and Wuhan is known as the most developed center in China. People drive to Wuhan from Xinyang on a daily basis. The chances for the disease to spread between the two cities are evident because any infected population in Wuhan, having interacted with anyone from Xinyang, can transmit the disease to Xinyang. The argument, therefore, shows that the short distance between Wuhan and Xinyang is one of the reasons for the spread of the coronavirus in Xinyang.

\section{Summary of Findings}

To summarize, it can be deduced from the findings that railway platforms play an important role in the spread of the coronavirus. This study shows that among other reasons, the spread of the virus in China is due to the distance between the cities and people traveling among different cities through the railway. Wuhan is known to be the most populated province of China and Hubei is identified as a hub of traveling and transport in the country. The railway line leaving Wuhan carries approximately 43,000 passengers daily to different cities. The large amount of people traveling from Wuhan to nearby cities results in the spread of the disease to these cities and nearby areas too. However, the findings also report on the effectiveness of control measures taken by the railway authorities. It can be deduced from the findings of this study that measures such as lockdown, the use of masks, sanitization, and social distancing have been proven 


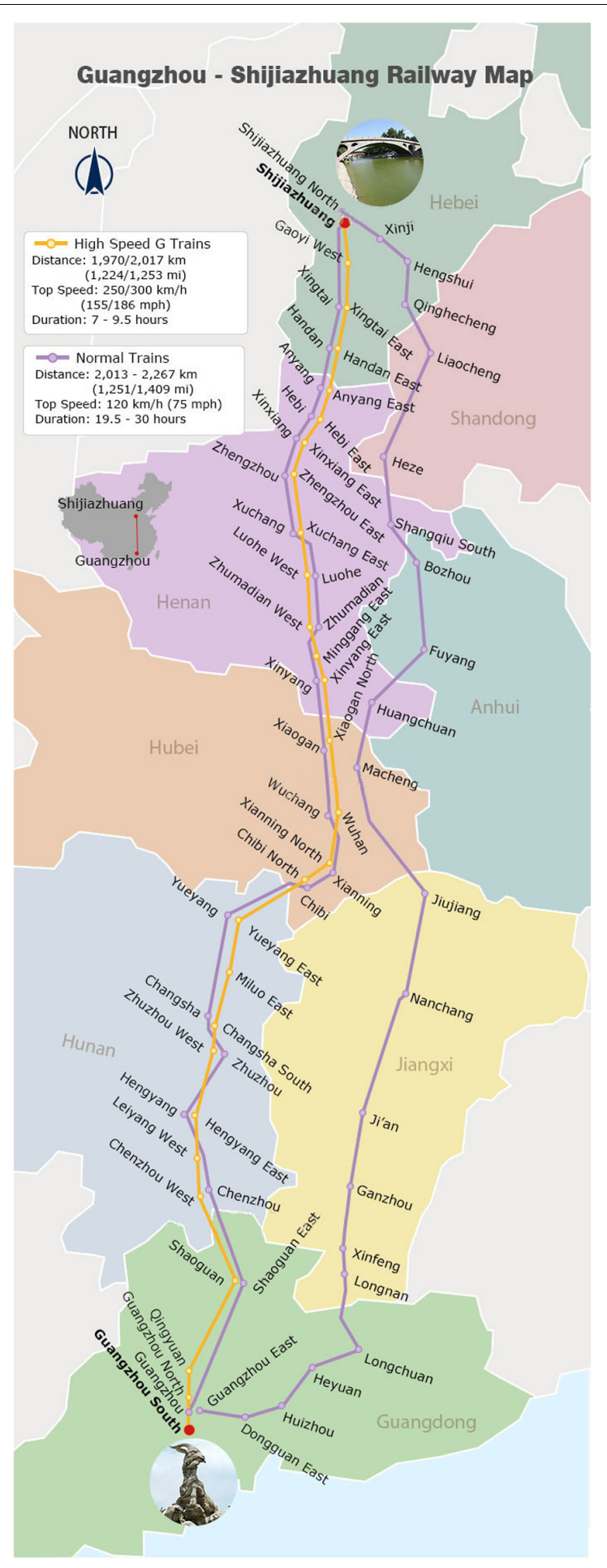

FIGURE 7 | Demonstration of areas with high prevalence of the coronavirus (Travel China Guide, 2020).

to be beneficial for controlling the spread of the coronavirus in China. In line with this, the next section highlights practical recommendations so that the disease could be controlled further.

\section{CONCLUSION AND RECOMMENDATIONS}

It has been shown in this study that Wuhan is located in one of the most populous provinces, which is an indicator of the quick spread of the disease in this city. Although the topic of the coronavirus is gaining increasing significance in the body of research, there lies a gap in analyzing the spread of the disease through rail transport in China. This is why the current study has adopted a case-study approach to evaluate the topic, considering the case of the Wuhan-Beijing railway line. Findings from the literature reveal a notable concentration of coronavirus cases in Wuhan (Ranasinghe et al., 2020). Apart from its large population, the notable inflow and outflow of people in Wuhan are a big reason for the spread of the disease. In addition to that, the current study has collected data through primary sources from experienced railway officials. Findings from the primary data are found to support the extant studies, except at particular points. It has been shown that transport through the WuhanBeijing railway line has contributed significantly to the spread of the disease. The imposition of lockdowns and the emphasis on practices such as social distancing and wearing safety masks are found to be effective in protecting people from the disease. However, findings reveal an evident abnormality in Wuhan even after lifting the lockdown, and so authorities should consider the following recommendations, so that the physical and mental wellbeing of the people is guaranteed.

- After the lockdown, an immense outflow of people from Wuhan is expected. Studies (Saadat et al., 2020) report that around 55,000 people were expected to leave Wuhan once the lockdown was lifted. In order to sustain the low figures of the coronavirus, the railway authorities should still keep in consideration the practices of social distancing. The authorities should be cautious of the times when the railway stations are likely to be packed and expand their infrastructure in a way that the expected outflow of people can be handled while maintaining a safe distance between passengers. It has also been shown that even after the cancellation of lockdown, the railway authorities should continue taking protective measures (Khan et al., 2020).

- The railway officials should ease the fears of the people by posting motivating signboards at different places in railway stations. Given the most unexpected outcomes of the pandemic, people will be scared to move across different cities. Thus, the railway authorities should follow the recommendation of Fine and Rajput (2020) and spread smiles for people who have survived the crisis.

- The railway authorities should install a system of testing for coming to railway stations. Although the government mandated measuring temperatures of people moving during the lockdown, a test should be done so that any person with symptoms of the coronavirus could be deterred from entering the premises or traveling through the railway. Besides this, the authorities should make sure that people wear masks and sanitize themselves regularly. The authorities should be considerate about installing hand 
sanitizer and free masks at different spots in the railway station, as well as in trains. This way, the chances for the coronavirus to spread again will be minimized.

- Although the lockdown has been lifted in Wuhan, there are only a few people on roads and on public transport. This can be accredited to the wave of fear that this pandemic has left among people. In order to comfort passengers, the railway authorities should share public service messages using the most popular media like TV ads and WeChat. As also recommended by researchers (Hunter et al., 2016), sharing encouraging messages with the people surviving the crisis will help build positivity among them. The city which was once a metropolitan hub is now deserted and destitute. While the economic shock is harsh, societal wellbeing has also been harmed, and needs to be restored.

By acting upon these recommendations, the government of Wuhan and the railway authorities will gradually overcome the shock that the coronavirus has caused. The ultimate aim of the railway authorities should be to sustain not only their economic profits but the wellbeing and betterment of their society too.

\section{Strengths and Limitations of the Study}

The study has quantitatively emphasized the role of railway platforms in the spread of the coronavirus in China. The key strengths of this study include the reliance on primary data, the use of a quantitative methodology, and the production of credible findings. Having used the quantitative method, the findings of this study are generalizable too. Moreover, the study has taken into account a rather untapped area of research. Given the extant literature, it is evident that the research is scarce on the role of railway platforms in the spread of the coronavirus in China. Thus, this study has attempted to bridge this gap while further extending the literature too. The recommendations proposed in this study also play a part in controlling the spread of this disease in China. However, there are also several limitations. For instance, there are several objective and unavoidable errors in the methodological choices of the study. Given the ethical considerations, the researcher could not force any respondent to participate in the study. This resulted in some missing answers from the respondents. Moreover, the sample respondents, who were the managers at Wuhan railway station, submitted their responses in a rush due to their busy schedules. Due to the evident situation of the pandemic, the researcher could not meet the respondents in person, which indicates a chance for the responses to be inaccurate. In addition to this, the sample size taken for the study is not an accurate and realistic representative of the entire population. Although the data collected from this sample size has resulted in the support of the objectives, the findings are not as comprehensive as they could have been in the case of a larger sample size. Apart from the methodological choices, another key limitation was the limited scope of the study. The researcher centered the findings on Wuhan railway station only. However, the study could have covered other nearby railway stations and the flow of people from those areas too. Nonetheless, the researcher has tried to deduce high-quality findings by respecting all the ethical standards.

\section{DATA AVAILABILITY STATEMENT}

The original contributions presented in the study are included in the article/supplementary material, further inquiries can be directed to the corresponding author.

\section{ETHICS STATEMENT}

Ethical review and approval was not required for the study on human participants in accordance with the local legislation and institutional requirements. Written informed consent from the participants was not required to participate in this study in accordance with the national legislation and the institutional requirements.

\section{AUTHOR CONTRIBUTIONS}

RL and DL: data collection, conceptualization, investigation, methodology, simulation, and writing - original draft preparation. SK: supervision, project administration, funding acquisition, conceptualization, methodology, and writing review and editing. All authors contributed to the article and approved the submitted version.

\section{FUNDING}

This research was funded by the European Commission for the financial sponsorship of the H2020-RISE Project No. 691135. The APC is kindly sponsored by Frontiers' COVID19 Open Science Initiative.

\section{ACKNOWLEDGMENTS}

The authors are sincerely grateful to the European Commission for the financial sponsorship of the H2020-RISE Project No. 691135 "RISEN: Rail Infrastructure Systems Engineering Network," which enables a global research network that tackles the grand challenge of railway infrastructure resilience and advanced sensing in extreme environments (www.risen2rail.eu) (Hunter et al., 2016). SK wishes to thank the Australian Academy of Science and the Japan Society for the Promotion of Science for his Invitation Research Fellowship (Long-term), Grant No. JSPS-L15701 at the Railway Technical Research Institute and the University of Tokyo, Japan. 


\section{REFERENCES}

Anthony, S. J., Johnson, C. K., Greig, D. J., Kramer, S., Che, X., Wells, H., et al. (2017). Global patterns in coronavirus diversity. Virus Evol. 3, 89-99. doi: $10.1093 / \mathrm{ve} / \mathrm{vex} 012$

Ayittey, F. K., Dzuvor, C., Ayittey, M. K., Chiwero, N. B., and Habib, A. (2020). Updates on Wuhan 2019 novel coronavirus epidemic. J. Med. Virol. 92:403. doi: 10.1002/jmv.25695

Balkhair, A., Al Maamari, K., and Alawi, F. B. (2017). The struggle against MERS-CoV (the novel coronavirus). Oman Med. J. 28:226. doi: 10.5001/omj. 2013.66

BBC China (2020). Death Toll Climbs to 106 as China tightens Measures. [Online]. Available online at: https://www.bbc.com/news/world-asia-china51275896 (accessed May 4, 2020).

Bloomberg News (2020). Coronavirus Spread in China Slows Sharply but Doubt Remains . [Online]. Available online at: https://www.bloomberg.com/ news/articles/2020-03-04/coronavirus-spread-in-china-slows-drastically-butdoubt-remains (accessed May 4, 2020).

Bramley, I., Goode, A., Anderson, L., and Mary, E. (2018). Researching in-store, at home: using virtual reality within quantitative surveys. Int. J. Market Res. 60, 344-351. doi: 10.1177/1470785318767287

Cascella, M., Rajnik, M., Cuomo, A., Dulebohn, S. C., and Di Napoli, R. (2020). "Features, evaluation and treatment coronavirus (COVID-19)," in Statpearls [internet], (Treasure Island, FL: StatPearls Publishing). Available online at: https://www.ncbi.nlm.nih.gov/books/NBK554776/ (accessed October 4, 2020).

Chang, D., Xu, H., Rebaza, A., Sharma, L., and Cruz, C. S. D. (2020). Protecting health-care workers from subclinical coronavirus infection. Lancet Respir. Med. 8:e13. doi: 10.1016/s2213-2600(20) 30066-7

Clifton, K., and Carrasco, J. A. (2018). Workshop synthesis: measuring attitudes and perceptions in quantitative surveys. Transportation Res. Proc. 32, 495-500. doi: 10.1016/j.trpro.2018.10.040

Fine, L., and Rajput, V. (2020). The smile is stronger than the handshake. MedEdPublish 9, 2-3. doi: 10.15694/mep.2020.000068.1

Goscé, L., and Johansson, A. (2018). Analysing the link between public transport use and airborne transmission: mobility and contagion in the London underground. Environ. Health 17:84. doi: 10.1186/s12940-0180427-5

Heydari, S. S., and Mountrakis, G. (2018). Effect of classifier selection, reference sample size, reference class distribution and scene heterogeneity in per-pixel classification accuracy using 26 Landsat sites. Remote Sensing Environ. 204 648-658. doi: 10.1016/j.rse.2017.09.035

Hu, X., Zhao, S., Shi, F., Huang, J., and Shan, X. (2017). Circuity analyses of HSR network and high-speed train paths in China. PLoS One 12:89-99. doi: 10.1371/journal.pone.0176005

Hunter, M. L., Van Wassenhove, L. N., and Besiou, M. (2016). The new rules for crisis management. MIT Sloan Manage. Rev. 57:71

Jiao, J., Wang, J., and Jin, F. (2017). Impacts of high-speed rail lines on the city network in China. J. Transport Geogr. 60, 257-266. doi: 10.1016/j.jtrangeo. 2017.03.010

Jung, S. M., Akhmetzhanov, A. R., Hayashi, K., Linton, N. M., Yang, Y., Yuan, B., et al. (2020). Real-time estimation of the risk of death from novel coronavirus (COVID-19) infection: inference using exported cases. J. Clin. Med. 9:523. doi: $10.3390 /$ jcm 9020523

Katz, R., Vaught, A., and Simmens, S. J. (2019). Local decision making for implementing social distancing in response to outbreaks. Public Health Reports 134, 150-154. doi: 10.1177/0033354918819755

Khan, S., Ali, A., Siddique, R., and Nabi, G. (2020). Novel coronavirus is putting the whole world on alert. J. Hosp. Infect. 104, 252-253. doi: 10.1016/j.jhin.2020. 01.019

Lai, T. H., Tang, E. W., Chau, S. K., Fung, K. S., and Li, K. K. (2020). Stepping up infection control measures in ophthalmology during the novel coronavirus outbreak: an experience from Hong Kong. Graefes Arch. Clin. Exp. Ophthalmol. 258, 1049-1055. doi: 10.1007/s00417-020-04641-8

Li, Z. C., and Sheng, D. (2016). Forecasting passenger travel demand for air and high-speed rail integration service: a case study of Beijing-Guangzhou corridor, China. Transportation Res. A Policy Pract. 94, 397-410. doi: 10.1016/j.tra.2016. 10.002
Liu, L. (2016). Using generic inductive approach in qualitative educational research: a case study analysis. J. Educ. Learn. 5, 129-135. doi: 10.5539/jel. v5n2p129

Lu, L., Liu, Q., Du, L., and Jiang, S. (2013). Middle East respiratory syndrome coronavirus (MERS-CoV): challenges in identifying its source and controlling its spread. Microbes Infect. 15, 625-629. doi: 10.1016/j.micinf.2013.06.003

Ma, X., Hu, X., and Schramm, D. (2020). "Effects of school activities on traffic flow on the example of traffic scenario from the city Wuhan," in Neue Dimensionen der Mobilität, ed. H. Proff (Wiesbaden: Springer Gabler), 153-163. doi: 10.1007/ 978-3-658-29746-6_14

Mizumoto, K., Kagaya, K., and Chowell, G. (2020). Early epidemiological assessment of the transmission potential and virulence of coronavirus disease 2019 (COVID-19) in Wuhan City: China, January-February, 2020. medRxiv [Preprint]. doi: 10.1186/s12916-020-01691-x

Nature (2020). Coronavirus: the First three Months as it Happened. [Online]. Available online at: https://www.nature.com/articles/d41586-020-00154-w (accessed May 4, 2020).

Otter, J. A., Donskey, C., Yezli, S., Douthwaite, S., Goldenberg, S. D., and Weber, D. J. (2016). Transmission of SARS and MERS coronaviruses and influenza virus in healthcare settings: the possible role of dry surface contamination. J. Hosp. Infect. 92, 235-250. doi: 10.1016/j.jhin.2015.08.027

Paradis, E., O’Brien, B., Nimmon, L., Bandiera, G., and Martimianakis, M. A. T. (2016). Design: selection of data collection methods. J. Graduate Med. Educ. 8:263. doi: 10.4300/jgme-d-16-00098.1

Pasley, J. (2020). These are the Everyday Objects to be Wary of Touching as the Coronavirus Spreads, and how to Adapt. [Online]. Available online at: https://www.businessinsider.com/photos-objects-wary-what-to-do-corona virus-spreads-2020-3 (accessed May 4, 2020).

Peeri, N. C., Shrestha, N., Rahman, M. S., Zaki, R., Tan, Z., Bibi, S., et al. (2020). The SARS, MERS and novel coronavirus (COVID-19) epidemics, the newest and biggest global health threats: what lessons have we learned? Int. J. Epidemiol. 49, 717-726. doi: 10.1093/ije/dyaa033

Ranasinghe, R., Damunupola, A., Wijesundara, S., Karunarathna, C., Nawarathna, D., Gamage, S., et al. (2020). Tourism after Corona: impacts of Covid 19 pandemic and way forward for tourism, hotel and mice industry in Sri Lanka. Hotel Mice Industry Sri Lanka 158, 4-10. doi: 10.2139/ssrn.3587170

Saadat, S., Rawtani, D., and Hussain, C. M. (2020). Environmental perspective of COVID-19. Sci. Total Environ. 728:138870. doi: 10.1016/j.scitotenv.2020. 138870

Shen, K., Yang, Y., Wang, T., Zhao, D., Jiang, Y., Jin, R., et al. (2020). Diagnosis, treatment, and prevention of 2019 novel coronavirus infection in children: experts' consensus statement. World J. Pediatr. 16, 223-231. doi: 10.1007/ s12519-020-00343-7

Shen, Q., Chen, P., and Pan, H. (2016). Factors affecting car ownership and mode choice in rail transit-supported suburbs of a large Chinese city. Transportation Res. A Policy Pract. 94, 31-44. doi: 10.1016/j.tra.2016. 08.027

Singhal, T. (2020). A review of coronavirus disease-2019 (COVID-19). Indian J. Pediatr. 87, 281-286. doi: 10.1007/s12098-020-03263-6

Tourangeau, R. (2018). "Maintaining respondent trust and protecting their data," in The Palgrave Handbook of Survey Research, eds D. Vannette and J. Krosnick (Cham: Palgrave Macmillan), 135-141. doi: 10.1007/978-3-319-543 95-6_18

Tracy, S. J. (2019). Qualitative Research Methods: Collecting Evidence, Crafting Analysis, Communicating Impact. Hoboken, NJ: John Wiley \& Sons.

Travel China Guide (2020). Guangzhou-Shijiazhuang Train . [Online]. Available online at: https://www.travelchinaguide.com/china-trains/guangzhou-shijia zhuang.htm (accessed May 28, 2020).

VOA News (2020). China's Virus Pandemic Epicenter Wuhan Ends 76-Day Lockdown. [Online]. Available online at: https://www.voanews.com/sciencehealth/coronavirus-outbreak/chinas-virus-pandemic-epicenter-wuhan-ends76-day-lockdown (accessed May 28, 2020).

Wang, C., Horby, P. W., Hayden, F. G., and Gao, G. F. (2020). A novel coronavirus outbreak of global health concern. Lancet 395, 470-473. doi: 10.1016/s01406736(20)30185-9

Wang, M. (2019). A retrospective and predictive study of fertility rates in China from 2003 to 2018. Heliyon 5:e01460. doi: 10.1016/j.heliyon.2019. e01460 
Wong, S. (2019). Number of Train Passengers in China from 2008 to 2018. [Online]. Available online at: https://www.statista.com/statistics/ 276054/number-of-train-passengers-in-china/. (accessed April 27, 2020).

Xinhua (2020). China Focus: Wuhan Urges Follow-up Supervision for over 30,000 Recovered Patients. [Online]. Available online at: http://www.xinhuanet.com/ english/2020-03/12/c_138870542.htm (accessed May 28, 2020).

Yang, Y., Peng, F., Wang, R., Guan, K., Jiang, T., Xu, G., et al. (2020). The deadly coronaviruses: the 2003 SARS pandemic and the 2020 novel coronavirus epidemic in China. J. Autoimmunity 109:102434. doi: 10.1016/j.jaut.2020. 102434

Zhao, S., Musa, S. S., Lin, Q., Ran, J., Yang, G., Wang, W., et al. (2020a). Estimating the unreported number of novel coronavirus (2019-nCoV) cases in China in the first half of January 2020: a data-driven modelling analysis of the early outbreak. J. Clin. Med. 9:388. doi: 10.3390/jcm9020388
Zhao, S., Zhuang, Z., Ran, J., Lin, J., Yang, G., Yang, L., et al. (2020b). The association between domestic train transportation and novel coronavirus (2019-nCoV) outbreak in China from 2019 to 2020: a data-driven correlational report. Travel Med. Infect. Dis. 33:101568. doi: 10.1016/j.tmaid.2020.101568

Conflict of Interest: The authors declare that the research was conducted in the absence of any commercial or financial relationships that could be construed as a potential conflict of interest.

Copyright (c) $2020 \mathrm{Liu}, \mathrm{Li}$ and Kaewunruen. This is an open-access article distributed under the terms of the Creative Commons Attribution License (CC BY). The use, distribution or reproduction in other forums is permitted, provided the original author(s) and the copyright owner(s) are credited and that the original publication in this journal is cited, in accordance with accepted academic practice. No use, distribution or reproduction is permitted which does not comply with these terms. 